\title{
Entrevista virtual al ex-magistrado auxiliar de la Sala Jurisdiccional Disciplinaria del Consejo Superior de la Judicatura: Doctor Alfonso Cajiao Cabrera
}

\section{Alfonso Cajiao Cabrera}

Con motivo de las diferentes propuestas de reforma a la justicia que se han venido debatiendo en los diferentes foros académicos, la Revista Jurídica Piélagus ha abordado este tema con una entrevista virtual realizada al doctor ALFONSO CAJIAO CABRERA, reconocido tratadista de temas de derecho público y ex-servidor del Estado. El doctor CAJIAO CABRERA es abogado de la Universidad Externado de Colombia, con postgrado en Alta Gerencia de la Universidad de los Andes y curso de postgrado en Derechos Fundamentales de la Universidad Carlos III de Madrid. Especializado en Disciplinario Cooperativa de Colombia. Ex funcionario de la Procuraduría General de la Nación, de la Empresa de Acueducto y Alcantarillado de Bogotá y ex magistrado auxiliar de la Sala de Jurisdiccional Disciplinaria del Consejo Superior de la Judicatura. Profesor Universitario. Actualmente se desempeña como Jefe de la Oficina de Control Disciplinario Interno de ECOPETROL S.A.

1. Diversos sectores políticos y académicos coinciden en afirmar que la justicia en Colombia se encuentra en crisis. ¿Cuál es su opinión sobre esta afirmación?

ALFONSO CAJIAO CABRERA: Desafortunadamente esto es cierto y estamos sobre diagnosticados en el tema. No obstante tal afirmación, cuyo escenario es necesariamente jurídico, debe acompañarse de un análisis más profundo sobre temas relativos a la idiosincrasia del colombiano en torno de varios elementos, que llevan a concluir que no toda la crisis es imputable a la misma justicia como rama del poder público. Veamos por ejemplo, el principio de buena fe y su desarrollo, pues desconfiamos de todo y de todos. Quiero decir que se trata de revisar también el aporte que el grado de desconfianza del colombiano para con sus congéneres se hace extensivo a sus instituciones y de otro lado, que tal forma de ver las cosas incide notoriamente en la cantidad de trámite y documentos que tienden a demostrar que si se comunicaron las actuaciones, que si se solicitaron los documentos, que el expediente si paso al despacho, que sí salió, que si se solicitó el peritazgo, la falta de credibilidad en la palabra, en la de todos, nos orienta a buscar en la actuación documental en el 
papel, la prueba de todas las actividades. Esas conocidas afirmaciones de: "pásame la solicitud por escrito», original y copia y entréguela en esa ventanilla y que le pongan sello de recibido», demuestran la tremenda desconfianza que habita en nosotros. Se mide la complejidad de un proceso en función del número de folios. Hay muchos trámites y todos se alimentan de los documentos en la administración de justicia, pero... ¿cuánto de ello es nutrido por la desconfianza entre nosotros mismos? Y, además esa cultura de que lo que no satisface de manera inmediata mis expectativas es malo y debo rechazarlo por corrupto. Si gano un pleito o se me absuelve, ;brilla la justicia! Pero si me condenan o sancionan o simplemente pierdo, es una injusticia o hay venalidad. Somos livianos en el verbo a la hora de criticar a los otros, y fanáticos del legalismo, pero ¿cuánto de lo que criticamos es fomentado por actitudes nuestras, impulsadas aún desde la academia o la política?

2. Una de las consecuencias de la crisis de la justicia está relacionada con la ilegitimidad e ingobernabilidad que genera. ¿Cómo hacerle frente a esta dificultad?

A.C.C. Somos hijos de una cultura de violencia, entendemos que no es el diálogo el instrumento para solventar los conflictos sino el ejercicio del poder o, en últimas, de la propia conveniencia. Desde Platón, Sócrates y Aristóteles se ha planteado que el derecho está al servicio de la justicia. El derecho es el instrumento que dinamiza los principios, y las leyes son una de sus expresiones. Debemos reflexionar para encontrar, auxiliados de la ética, fórmulas menos complejas que nos permitan solucionar los conflictos haciéndole culto más a la convivencia y a la armonía de las relaciones sociales que al legalismo. Debemos buscar el desarrollo de la justicia y no del imperio de la ley sin más consideraciones. De un modelo que articule los principios de libertad, democracia, solidaridad, igualdad, que rechacen la violencia como actitud. Estamos buscando efectos, vamos a las causas. El funcionamiento y la crisis de la justicia es un efecto, no una causa. Alcanzaremos legitimidad cuando resolvamos satisfactoriamente para las partes un conflicto. La crisis de la legitimidad debe verse más como un discurso proveniente de la insatisfacción de las demandas de la comunidad frente a la insuficiencia económica y política, que como un tema atañe exclusivamente a la rama judicial.

3. ¿Considera usted que Colombia vive hoy bajo el imperio del «Gobierno de los jueces»? ¿Por qué?

A.C.C. Esta consideración resume el tema. No. No. vivimos bajo el imperio de los jueces. Vivimos bajo el imperio de los derechos fundamentales. El Estado tiene, a partir de la Constitución Política de 1991, un papel que lo convierte al lado de la protección de los antiguos derechos individuales de libertad, en un 
Estado de bienestar que promueve los derechos sociales, la prosperidad general (trabajo, vivienda, salud, información, servicios públicos, ambiente, etc.). Un Estado comprometido con unos principios universales normados en la Constitución Política que implican que la validez de las leyes no está dada en atención a su mera existencia, a la producción de la misma por el órgano legislativo o el ejecutivo habilitado en facultades extraordinarias, sino en cuanto desarrollan estos principios inmanentes, no es la producción del derecho, y de la ley como su instrumento, la que lo legitima sino su contenido. Y como quiera que los jueces son los garantes de que las leyes tengan a partir de la Constitución ese contenido, se ha generado la sensación, alimentada muchas veces por tendencias coyunturales y antojadizas, de que son los jueces los que gobiernan.

\section{4. ¿Cómo evitar los enfrentamientos de poderes por los Jallos de la Corte Constitucional?}

A.C.C. Estamos asistiendo a un cambio de paradigma del estado de derecho, a una faceta superior del mismo, al estado constitucional, a la democracia constitucional garantista de los derechos fundamentales. La democracia también tiene sus límites, no es ya la tiranía de las mayorías o la omnipotencia de las mismas, las minorías también tienen derechos. No son los poderes políticos de las mayorías ni los poderes económicos del mercado los que predominan, también están en juego y en consideración los derechos de las minorías; las reglas han cambiado y entre más nos demoremos en aceptarlo más traumatismos habrá. La Corte Constitucional es el órgano que vela por el cumplimiento de los derechos fundamentales, por la supremacía de la constitución.

5. Las propuestas de reforma a la justicia, siempre han girado en torno a la modificación de la Acción de Tutela, a la limitación en las competencias de la Corte Constitucional o a la supresión del Consejo Superior de la Judicatura. Sin embargo, aspectos como la corrupción judicial, el exagerado Jormalismo, la parcialidad, la no independencia del poder judicial, la acumulación interminable de expedientes y el atraso tecnológico, son dejados como secundarios. ¿ En su criterio, para hacer frente a toda esta crisis, es necesario un cambio de paradigma en la concepción de la justicia como Junción esencial del Estado? ¿Cuál es su recomendación?

A.C.C. Creo haber aportado en mis respuestas anteriores, consideraciones a este punto. En efecto, ni la acción de tutela o la independencia que ha traído el Consejo Superior de la Judicatura a la rama judicial son causantes de las crisis, estamos buscando las causas de las crisis en sus remedios, estas instituciones han surgido de la crisis, no son sus causantes. La Constitución Política nos transformó el paradigma y asistimos perplejos al cambio, debemos asumirlo con prestancia y modelarnos de cara al futuro. Corrupción y formalismo excesivo 
son, razones de orden cultural que deben ser estudiadas. El dilema es del ethos funcionarial; quienes pertenecen al Estado deben comprender que se trata de habilitar un modelo de servicio; que el hecho de pertenecer a la función pública implica un compromiso ético y moral para con los habitantes del territorio nacional, que la administración pública es un enclave de servicio a la comunidad y que quienes tenemos el honor de servirla lo hacemos en el entendido de que nuestras actuaciones benefician a la comunidad.

Quizá lo más importante, ya para finalizar, es que la idea de la justicia como igualdad desarrollada en principios, es autonomía como libertad y solidaridad, aunadas al diálogo y a la tolerancia, nos proporcionarán el progreso que tanto necesita nuestra atribulada Colombia. 